\title{
Learning in the land snail (Helix aspersa Müller)*
}

\author{
R. K. SIEGEL and M. E. JARVIK \\ Departments of Pharmacology and Psychiatry, \\ University of California, Los Angeles \\ Los Angeles, California 90024
}

\begin{abstract}
A group of two experiments are discussed which demonstrate avoidance learning in land snails. Experiment I utilized the snail's negative geotaxis and its chemoreceptive characteristics and required the snail to climb a vertical pole which contained a quinine-saturated loop of thread at the top. Experiment II substituted electric shock loops for the quinine. Snails in both experimental groups manifested progressively increasing climbing latencies and avoidance responses throughout five successive training sessions and a one week retention test. Control animals which received noncontingent quinine or shock did not show evidence of learning. These results provide evidence of rapid avoidance learning in gastropod mollusks.
\end{abstract}

Very few investigators have examined the problem of learning in snails (see reviews by Stephens \& McGaugh, 1972; Willows, 1973). Early workers have suggested that these gastropods show evidence of classical conditioning (Thompson, 1917), maze learning (Garth \& Mitchell, 1926; Fischel, 1931), and habituation (Humphrey, 1930; Grindley, 1937). The phenomenon of classical conditioning in snails has been recently reexamined by Wells and Wells (1971), who concluded that changes in responses of Physa to electric shock conditioning could be more easily explained by sensitization rather than conditioning per se. The demonstration of maze learning in snails has also been disputed by Wells and Buckley (1972) who argue that there is no firm evidence that gastropods can learn to run mazes as a result of differential reinforcement. Rather, these authors aruge that the snails lay mucous trials whereever they go and respond to these cues on a trial and error basis. Such a process as the latter would still involve a learning mechanism but one which is probably mediated by chemoreception or pheromones in the trials. Habituation in snails is a much more reliable phenomenon (Cook, 1970) and even in snails with poorly developed cerebral ganglia such as Aplysia there is evidence for longer-term habituation of a defensive withdrawal reflex that persists for over three weeks (Carew et al, 1972; Carew \& Kandel, 1973; Pinsker et al, 1973). Habituation-like phenomenon has also been observed in the isolated neurons of Helix pomatia, but the retention period here is brief (Pusztai \& Adam, 1974).

Recently, Stephens and McGaugh (1972) investigated the biological factors related to learning in Helix aspersa and found such learning to be facilitated when tasks relevant to the natural biology of the species are considered. Utilizing the snail's negative geotaxis and its chemoreceptive characteristics, Stephens and McGaugh

*Supported by MH 23880-02 from N.I.M.H. We thank Scott Beadenkopf for techanical assistance. employed a pole-climbing response with quinine as an aversive stimulus at the top of the pole. These authors demonstrated both short- and long-term memory of the aversive experience as well as habituation of the climbing response itself with a neutral water stimulus. This learning appeared to be modifiable by length of laboratory housing, humidity, nutrition, and reproductive conditions.

The following experiments were designed to replicate the basic findings of Stephens and McGaugh and extend them to a situation in which electric shock was employed as the aversive stimulus. In addition, controls for exposure to the aversive stimulus were included.

\section{EXPERIMENT I}

\section{Method}

Subjects. Ss were 20 Helix aspersa collected 1 week before the experiment began from ivy patches on the University of California at Los Angeles campus. Average shell aperture diameter was $10 \mathrm{~mm}$. Animals were housed in plastic boxes containing moistened garden soil sprinkled with $\mathrm{CaCO}_{3}$ and supplied with free access to fresh lettuce. Animals were kept in a constant temperature of $23^{\circ} \mathrm{C}$ and in a 12-h day-night cycle. All experiments were conducted during daylight hours.

Apparatus. The training apparatus was similar to that described by Stephens and McGaugh (1972). It consisted of a set of glass rods (5-mm diam, 10-mm length) mounted upright $(90 \mathrm{deg})$ in a Plexiglas base. A cotton thread (Size 00) loop was tied $5 \mathrm{~mm}$ from the top of the glass rods.

Procedure. The training and testing procedures were similar to those described by Stephens and McGaugh (1972) with some modifications. The 20 animals were randomly divided into two groups of 10 animals each. Snails in the Quinine Group were trained on a set of rods, the threads of which contained $10 \mu 1$ of a saturated solution of quinine hydrochloride ( $\mathrm{pH} 2.6$ at $23^{\circ} \mathrm{C}$ ). Snails in the Water Group were trained on a set of rods, the threads of which contained $10 \mu 1$. of double-distilled water. At the start of each training trial, a snail was removed from the home container and placed at the base of the rod so that the anterior margin of the foot was touching the rod. As the snail started its climb up the rod, a timer was started as soon as the entire foot of the animal left the Plexiglas base. A naive snail placed in this situation will almost invariably start climbing because of a tendency to maximize the pull of the shell upon the 
dorsal body wall, a strong negative geotaxis. (For a complete description of this climbing behavior and associated motivational factors, see Stephens \& MoGaugh, 1972). The trial and trial timer were terminated when either one of three events occurred: (1) the anterior margin of the body made contact with the thread and retracted into the sheil; (2) the snail reversed direction and moved off the rod onto the base; or (3) $120 \mathrm{sec}$ elapsed. The snail was then removed from the rod and placed in a plastic holding box for a 90 -sec intertrial interval (ITI). The training procedure was repeated twice for a total of three trials each day. A clean rod and thread was used for each successive trial so as to control for the mucous trials and other spurious and perhaps more salient cues to the learning situation. At the end of each training session, animals in the water group and those in the quinine group who had not made contact with the quinine thread were briefly placed on a quinine thread fastened to a horizontal metal plate in order to equate exposure to this stimulus. All animals were then rinsed in double-distilled water and returned to their home containers. Each animal received five daily training sessions of three trials each. At 1 week ( 7 days) following termination of training, all animals received a retest session consisting of three regular training trials.

\section{Results and Discussion}

The results are shown in Fig. 1 in terms of the mean time in seconds for climbing the rods plotted against trial number and session number. Animals exceeding the 120 -sec time limit were assigned latencies of $120 \mathrm{sec}$. Animals reversing direction and moving off the rod within the $120-\mathrm{sec}$ trial were also assigned latencies of $120 \mathrm{sec}$. It is clear from Fig. 1 that quinine animals manifested consistently higher latencies than water animals on all training trials. Quinine latencies were significantly higher than water latencies (Wilcoxon matched-pairs signed-rank test, one tailed) on.training Trial 1 in all sessions starting on the second day. This indicates a 24-h retention of the aversive stimulus for quinine-treated snails.. However, while quinine animals showed higher latencies on the 1-week retention test, these were not statistically significant due to a large between Ss variance. Table 1 shows the total avoidance

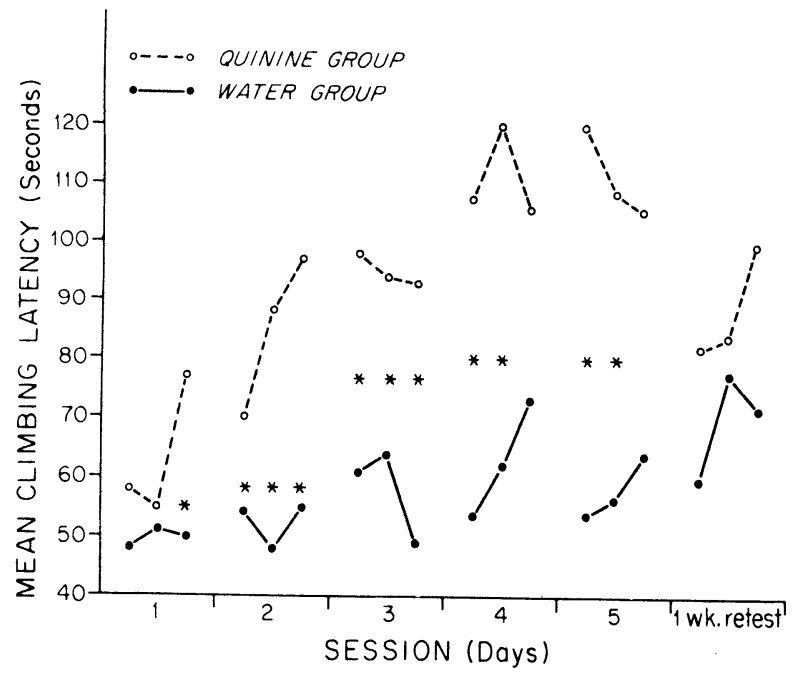

Fig. 1. Mean climbing latencies for each group of snails in each trial and session in Experiment I. An asterisk indicates significant difference between groups at that point (Wilcoxon, $\mathrm{p}=.025$ ).
Table 1

Total Number of Animals Executing Avoidance Responses in Each Session and Trial in Experiment $I(N=10)$

\begin{tabular}{cccc}
\hline Session & Trial & $\begin{array}{c}\text { Quinine } \\
\text { Group }\end{array}$ & $\begin{array}{c}\text { Water } \\
\text { Group }\end{array}$ \\
\hline \multirow{2}{*}{1} & 1 & 0 & 0 \\
& 2 & 0 & 1 \\
2 & 3 & 0 & 0 \\
& 1 & 2 & 0 \\
3 & 2 & 2 & 0 \\
& 3 & 2 & 0 \\
& 1 & 1 & 0 \\
4 & 2 & 1 & 1 \\
& 3 & 2 & 1 \\
\multirow{3}{*}{5} & 1 & 1 & 0 \\
& 2 & 2 & 0 \\
& 3 & 1 & 1 \\
Retest & 1 & 0 & 0 \\
& 2 & 0 & 0 \\
Total & 3 & 0 & 0 \\
\hline
\end{tabular}

responses (number of animals reversing direction and moving off the rod within $120 \mathrm{sec}$ ) for each group in each trial and session number. Here it can be seen that a total of 15 avoidances occurred for the quinine group throughout training while there were only four avoidances for the water group. Taken together, these data replicate the major findings of Stephens and McGaugh (1972) that learning can occur in Helix in this situation. In addition, the progressive increase in latencies for the water group indicates habituation to the climbing response itself. This latter result may partially account for the loss of significance in the comparisons of retest latencies.

\section{EXPERIMENT II}

Experiment II was designed to assess learning in the snail using electric shock as the aversive stimulus. This experiment was basically a follow-up study of an earlier unpublished finding (Stephens, 1971, personal communication).

\section{Method}

Subjects. Ss were 20 new Helix aspersa collected and housed as described in Experiment I.

Apparatus. The apparatus was similar to that in Experiment I with the exception that hollow Plexiglas rods were substituted for the glass rods. Two loops of bare silver wire were placed around the top of each rod at $10 \mathrm{~mm}$ and $5 \mathrm{~mm}$ from the top. These wires ran through the hollow rods and were connected to a 28-V DC power supply.

Procedure. The 20 snails were randomly divided into two groups of 10 snails each. Snails in the shock group received five daily training sessions of three trials each with the shock circuit activated. Snails in the no-shock group were run according to the same procedure, but the shock was unavailable for this group. At the start of each training trial, a snail was removed from the home container and placed at the base of the rod so that the 
anterior margin of the foot was touching the rod. As the snail started its climb up the rod, a timer was started as soon as the foot of the animal left the base. The timer and trial were terminated when either of three events occurred: (1) when the snail crossed the top wire loop which completed the shock circuit and stopped the timer; (2) when the snail reversed direction and moved off the rod onto the base; or (3) when $300 \mathrm{sec}$ elapsed. When the snails in the shock group crossed the top wire, they received a constant shock until the body retracted into the shell or the animal moved away from the to $p$ loop and broke the circuit. The snail was then removed from the rod and placed in a plastic container for a $90-\mathrm{sec}$ ITI. At the end of each training session, snails in the no-shock group and those in the shock group who had not received electric shock were briefly exposed to an electric shock loop mounted on a horizontal wooden base. This lat ter procedure was included so as to control for effects of noncontingent aversive stimulation. All snails were then rinsed in double-distilled water and returned to the home containers. A clean rod was used for each snail on each day, and five daily training sessions were administred followed by a 1 -week retention test.

\section{Results and Discussion}

The results are shown in Fig. 2 in terms of the mean climbing latencies for each trial number and session number. Animals exceeding the 300-sec limit were assigned latencies of $300 \mathrm{sec}$. Animals reversing direction and moving off the rod within the 300 -sec trial were also assigned latencies of $300 \mathrm{sec}$. As can be seen from Fig. 2, animals in the shock group start to show longer latencies in Session 2 than the no-shock animals. This trend becomes significant in Session 3 and continues throughout the first two trials of the 1-week retest session as well. Table 2 shows each Group's total avoidance responses (number of animals reversing direction and moving off the rod within $300 \mathrm{sec}$ ) as a function of trial number and session number. Here it crn be seen that only two avoidances occurred in

Table 2

Total Number of Animals Executing Avoidance Responses in Each Session and Trial in Experiment II $(N=10)$

\begin{tabular}{|c|c|c|c|}
\hline \multirow[b]{2}{*}{ Session } & \multirow[b]{2}{*}{ Trial } & \multicolumn{2}{|c|}{ Group } \\
\hline & & Shock & No Shock \\
\hline 1 & $\begin{array}{l}1 \\
2 \\
3\end{array}$ & $\begin{array}{l}0 \\
0 \\
0\end{array}$ & $\begin{array}{l}0 \\
0 \\
0\end{array}$ \\
\hline 2 & $\begin{array}{l}1 \\
2 \\
3\end{array}$ & $\begin{array}{l}0 \\
0 \\
1\end{array}$ & $\begin{array}{l}0 \\
0 \\
0\end{array}$ \\
\hline 3 & $\begin{array}{l}1 \\
2 \\
3\end{array}$ & $\begin{array}{l}0 \\
0 \\
0\end{array}$ & $\begin{array}{l}0 \\
0 \\
0\end{array}$ \\
\hline 4 & $\begin{array}{l}1 \\
2 \\
3\end{array}$ & $\begin{array}{l}1 \\
1 \\
4\end{array}$ & $\begin{array}{l}0 \\
1 \\
0\end{array}$ \\
\hline 5 & $\begin{array}{l}1 \\
2 \\
3\end{array}$ & $\begin{array}{r}10 \\
6 \\
7\end{array}$ & $\begin{array}{l}0 \\
0 \\
1\end{array}$ \\
\hline Retest & $\begin{array}{l}1 \\
2 \\
3\end{array}$ & $\begin{array}{l}2 \\
1 \\
0\end{array}$ & $\begin{array}{l}0 \\
0 \\
0\end{array}$ \\
\hline Total & & 33 & 2 \\
\hline
\end{tabular}

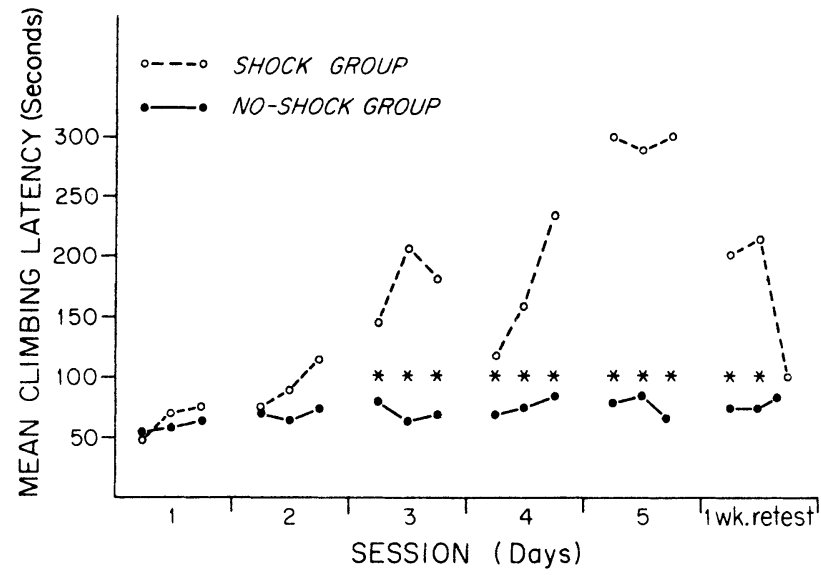

Fig. 2. Mean climbing latencies for each group of snails in each trial and session in Experiment II. An asterisk indicates a significant difference between groups at that point (Wilcoxon, $\mathrm{p}=.025)$.

no-shock group (one each on Days 4 and 5). However, in the shock group, four avoidances were recorded by the end of Session 4 and a surprising 10 avoidances in Trial 1 of Session 5. The number of avoidances for the shock group gradually declined during the 1-week retest, but latencies remained significantly higher than no-shock controls. Thus, these data indicated that avoidance learning can occur in Helix aspersa when electric shock is used as the aversive stimulus. Such learning, measured by progressively increașing climbing (approach) latencies and increasing avoidance responses, appears to be significantly more effective than quinine treatment in producing 1-week retention of the learned response.

\section{REFERENCES}

Carew, T. J., Pinsker, H. M., \& Kandel, E. R. Long-term habituation of a defensive withdrawal reflex in Aplysia. Science, 1972, 175, 451-454.

Carew, T. J., \& Kandel, E. R. Acquisition and retention of a long-term habituation in Aplysia: Correlation of behavioral and cellular process. Science, 1973, 182, 1158-1160.

Cook, A. Habituation in a freshwater snail (Limnaea stagnalis). A nimal Behavior, 1970, 178, 463-474.

Fischel, W. Dressurversuche an Schnecken. Zeitschrift für vergleichende Physiologie, 1931, 15, 50-70.

Garth, T. R., \& Mitchell, M. P. The learning curve of a land snail. Journal of Comparative Psychology, 1926, 6, 103-113.

Grindley, G. C. The intelligence of animals. London, 1937.

Humphrey, G. Le Chatelier's rule and the problem of habituation and dehabituation in Helix albolabris. Psychologische Forschung, 1930, 13, 113-127.

Pinsker, H. M., Hening, W. A.. Carew, T. J., \& Kande., E. R. Long-term sensitization of a defensive withdrawal reflex in Aplysia. Science, 1973, 182, 1039-1042.

Pusztai, J., \& Adam, G. Learning phenomena in the giant neurons of the snail (Helix Pomatia). Comparative Biochemistry \& Physiology, 1974, 47A, 165-171.

Stephens, G. J., \& McGaugh, J. L. Biological factors related to learning in the land snail Helix aspersa Müller, Animal Behavior, 1972, 20, 309-315.

Thompson, E. L. An analysis of the learning process in the snail Physa gyrina Say. Behavior Monographs, 1917, 3 (14), 1-89.

Wells, M. J., \& Buckley, S. K. L. Snails and trials. A nimal Behavior, 1972, 20, 345-355.

Wells, M. J., \& Wells, J. Conditioning and sensitization in snails. A nimal Behavior, 1971, 19, 305-312.

Willows, A. O. D. Learning in gastropod mollusks. In W. C. Corning, J. A. Dyal, and A. O. D. Willows (Ed.) Invertebrate learning. New York: Plenum Press, 1973, 187-273. 